\title{
A dialética do ensino e da aprendizagem na atividade pedagógica histórico-crítica
}

Tiago Nicola Lavoura(a)

Lígia Márcia Martins(b)

Lavoura TN, Martins LM. The dialectic of teaching and learning in historical-critical educational activity. Interface (Botucatu). 2017; 21(62):531-41.

Through the intermediation between the historical-critical pedagogy and historical-cultural psychology based on the fundamentals of historical and dialectical materialism, the paper aims to discuss the dialectic of teaching and learning in the educational activity. It aims to contribute to overcome the split between ontology and epistemology, by pointing out the need for a solid understanding of the fundamentals of the ascension from the abstract to the concrete method while proposing the activity theory as an indispensable theoretical stuff to think about the organization of educational activity of teaching and learning in the field of education. In this way it puts in motion the teaching method needed for the apprehension of phenomena as synthesis of multiple determinations and relations.

Keywords: Method. Pedagogical activity. Teaching. Learning.
Explicitando as intermediações entre a pedagogia histórico-crítica e a psicologia histórico-cultural a partir dos fundamentos do materialismo histórico-dialético, o artigo pretende problematizar a dialética do ensino e da aprendizagem na atividade pedagógica. Enseja-se contribuir para a superação do problema da cisão entre ontologia e epistemologia ao apontar a necessidade da sólida compreensão dos fundamentos do método de ascensão do abstrato ao concreto, ao passo que se afirma a teoria da atividade como estofo teórico imprescindível para se pensar a organização da atividade pedagógica de ensino e aprendizagem no âmbito da educação, colocando em movimento o método pedagógico necessário para a apreensão dos fenômenos como síntese de múltiplas determinações e relações numerosas.

Palavras-chave: Método. Atividade pedagógica. Ensino. Aprendizagem.

\footnotetext{
(a) Departamento de Ciências da Saúde, Universidade Estadual de Santa Cruz. Rodovia Jorge Amado, $\mathrm{Km}$ 16. Ilheus, BA, Brasil. 45662-900 nicolalavoura@ uol.com.br

(b) Departamento de Psicologia, Faculdade de Ciências de Bauru, Universidade Estadual Paulista "Júlio de Mesquita Filho". Bauru, SP, Brasil. ligiamar@fc.unesp.br
} 


\section{Introdução}

Tornou-se um tanto conhecido o método da pedagogia histórico-crítica, anunciado por Saviani ${ }^{1}$ como processo constituído por cinco passos, tendo em vista instrumentalizar uma didática que contraponha a didática da pedagogia histórico-crítica (partindo do materialismo histórico-dialético) à didática da pedagogia tradicional (com base no método expositivo formulado por Herbart, fundado no método científico indutivo de Bacon) e da Escola Nova (com base no método experimentalista ao qual se filia Dewey).

Desde sua proposição metodológica, já se apontava para o fato de não se incorrer no erro de tomar os referidos passos como uma sequência cronológica. Conforme Saviani1 asseverou: "[...] em lugar de passos que se ordenam numa sequência cronológica, é mais apropriado falar aí de momentos articulados num mesmo movimento, único e orgânico." (p. 67, destaque nosso).

Como forma de exemplificação, o referido autor afirmou que, em muitos casos, a problematização exige a instrumentalização, uma vez que a capacidade de problematizar algum dado constitutivo da prática social depende diretamente da posse de determinados instrumentos, vale dizer, de conhecimentos sobre tal. Posteriormente, Saviani ${ }^{2}$ passou a empregar o termo "momentos", buscando corrigir equívocos de entendimento do método pedagógico proposto.

Assim, tais momentos do método pedagógico articulam-se dialeticamente no trabalho educativo, sempre considerando a prática social dos homens como ponto de partida e de chegada da prática educativa, tomando como momentos intermediários a problematização dessa prática social, a instrumentalização dos alunos - compreendida como a apropriação dos instrumentos teóricos e práticos necessários à transformação da prática social - e a "catarse", que corresponde à efetiva incorporação dos instrumentos culturais, transformados em elementos ativos de transformação social ${ }^{2}$.

Desde então, temos acompanhado, sobretudo ao longo desses últimos anos, uma crescente produção acadêmica nos mais diversos campos e áreas do saber científico, que têm buscado discutir o ensino dos conteúdos escolares a partir dos fundamentos da pedagogia histórico-crítica, apresentando formas para o ensino de Ciências, Matemática, Geografia, Educação Física, Química, Filosofia, Artes, entre outras disciplinas do currículo escolar dos diferentes níveis de ensino.

A despeito dessas inúmeras colaborações que se somam aos esforços da construção coletiva da pedagogia histórico-crítica, enseja-se neste artigo problematizar a discussão acerca do método dessa teoria pedagógica tal como se apresenta nas referidas produções, notadamente, tendo-se como preocupação central o que aqui se denomina por uma - possível e, em alguns casos, notória "didatização e desmetodização do método da pedagogia histórico-crítica".

É válido pressupor alguns nexos causais que possibilitam explicar essa didatização e desmetodização do método pedagógico histórico-crítico, quais sejam: a) a incompreensão do caráter dialético do método pedagógico, o que leva à sua formalização expressa em passos lineares e mecânicos, sequencialmente sistematizados a partir da lógica formal do pensamento, incorrendo-se na didatização do ensino; b) a inadequada caracterização do conceito de mediação presente nessa teoria pedagógica (enquanto interposição que gera transformação), comprometendo a compreensão, por exemplo, da relação teoria e prática e da relação forma-conteúdo-destinatário; c) a falta de clareza na distinção entre método e procedimentos de ensino, com nítida hipertrofia do segundo e secundarização ou abandono d' (o primeiro, levando consequentemente à desmetodização do próprio método; e d) por fim, um pretenso epistemologismo da pedagogia histórico-crítica, de forma intencional ou não, por parte daqueles que o fazem, muito ao gosto da ambiência contemporânea identificada com o debate pós-moderno, debruçando-se em torno de seus apontamentos didático-metodológicos sem, no entanto, lançar mão da apropriação de suas bases teóricas e históricas, seus fundamentos filosóficos e o significado político do conjunto da obra de Dermeval Saviani, o que leva à interdição da verdadeira concepção ontológica da pedagogia histórico-crítica.

O caminho por nós escolhido neste artigo, a fim de contribuir para as necessárias superações desses equívocos, está delineado no ponto de partida pela afirmação de uma sólida compreensão acerca dos fundamentos da teoria social de Marx ${ }^{3}$; notadamente, seu método de apreensão do movimento do conhecimento do real concreto em direção ao concreto pensado (que, por sua vez, dá suporte 
ao método pedagógico histórico-crítico), tendo em vista a apropriação, por parte dos educandos, do conjunto dos conhecimentos historicamente desenvolvidos pela humanidade. Essa é uma exigência para aqueles que almejam desenvolver seu trabalho pedagógico com base na pedagogia históricocrítica. O ponto de chegada do presente ensaio está na análise do duplo trânsito requerido pelo trabalho pedagógico no que se refere ao caminho lógico do ensino em contraposição dialética ao da aprendizagem, processo dinamicamente promotor de desenvolvimento humano, conforme apontamentos da psicologia histórico-cultural e da teoria da atividade de Leontiev ${ }^{4,5}$.

A proposição da contradição lógica existente entre os processos de ensino e de aprendizagem não tem por base níveis de ensino ou áreas específicas do conhecimento, mas características evidenciadas pela psicologia histórico-cultural e pedagogia histórico-crítica acerca da relação entre os atos de ensinar e aprender. Trata-se, pois, de um princípio orientador para a organização didática do trabalho pedagógico, aplicando-se desde a educação básica ao ensino superior, e igualmente para pósgraduação e formação profissional contínua. Ou seja, aplica-se às situações nas quais interagem, de modo sistematizado, alguém na condição de aprendiz e alguém na condição de promotor da referida aprendizagem. O mesmo é possível afirmar no que se refere ao problema da procedimentalização do ensino, ou seja, o que aqui estamos denominando de didatização da atividade educativa.

Nesse sentido, ao explicitar as intermediações entre a pedagogia histórico-crítica e a psicologia histórico-cultural sob os fundamentos do materialismo histórico-dialético, pretendemos contribuir para a efetivação de uma prática pedagógica que supere os possíveis equívocos de didatização e desmetodização da atividade de ensino.

\section{O método em Marx: constituição da teoria social e fundamento da pedagogia histórico-crítica}

Como se sabe, Marx jamais escreveu um tratado acerca do método por ele operado para compreender seu objeto de análise com vistas à intervenção prática-política. Algumas poucas páginas da obra do filósofo são destinadas à discussão sobre o método.

Tal fato se torna evidente quando se compreende que Marx jamais reduziu suas análises à discussão epistemológica, interditando a impostação ontológica necessária à apreensão do real em pensamento. Não há em Marx um reducionismo epistemológico, por assim dizer, um epistemologismo, entificando a razão, desprezando a história e supondo que os problemas do real possuem raiz na maneira de se pensar sobre esse real, o que se coloca na contracorrente do pensamento moderno em sua fase de decadência ideológica ${ }^{6}$, seja nos períodos de "miséria da razão" - expressão do racionalismo formal ou em períodos de irracionalismo - expressos por teorias sedimentadas no subjetivismo?.

Dessa maneira, não é possível compreender o método em Marx independente do espírito de sua obra, visto não haver nesse autor um tratamento metodológico autônomo, no qual se formalizam e cristalizam regras e técnicas supostamente científicas, independente do objeto que se quer apreender.

Conforme Hungaro ${ }^{8}$, o que há em Marx é a constituição da mais bem elaborada teoria social na modernidade, deixando-nos como herança não um novo paradigma de análise ou uma nova abordagem metodológica, mas sim a mais fecunda elaboração teórica rica em determinações da própria organização social do objeto em análise: o modo de produção capitalista.

Marx buscou ao longo de seus disciplinados e extenuantes estudos reproduzir em pensamento o movimento real de seu objeto de análise, tornando lógico o movimento histórico de gênese, desenvolvimento, consolidação e decadência da ordem burguesa, tendo como fonte a análise crítica da economia política clássica, da filosofia alemã e do pensamento político socialista francês vinculado à tradição e luta operária ${ }^{9}$. Nessas bases, elaborou uma concepção ontológica de teoria, que the possibilitou constituir idealmente a processualidade, o movimento e o vir a ser do seu objeto investigativo, operando com categorias analíticas expressivas do modo de ser do objeto, configuradas como determinações da existência e como traços efetivos da própria realidade, carregadas de elementos de continuidade e superação que se sintetizam em uma complexa totalidade social ${ }^{8}$.

É nesse sentido que a riqueza metodológica de Marx não pode ser compreendida à revelia de sua teoria, o que implica conhecer a teoria para apreender o método, pois caso contrário caímos na 
epistemologização teórico-metodológica (por certo, um epistemologismo). As análises de Lukács ${ }^{6,10}$ quanto ao que denominou de decadência ideológica da filosofia burguesa evidenciam o processo de corrosão da dimensão ontológica das teorias científicas e filosóficas, a partir do momento em que a burguesia não mais se encontra na condição de classe revolucionária, mas sim na condição de classe conservadora do existente. $\mathrm{O}$ traço peculiar desse pensamento decadente diz respeito à apresentação de respostas evasionistas em face dos dilemas da realidade histórico-social.

De acordo com Coutinho ${ }^{7}$, o período da decadência da filosofia burguesa passa a oscilar entre uma razão miserável - típica do racionalismo formal demarcado por um epistemologismo que passa a ter como substrato a liquidação da dimensão ontológica na análise de qualquer objeto do conhecimento (positivismo e neopositivismo) - e um característico irracionalismo, demarcado por categorias como pessimismo, intuição, subjetivismo e o existencialismo individualista (fenomenologia e existencialismo).

No campo educacional, entendemos que as hegemônicas pedagogias do "aprender a aprender"11, denominadas por alguns autores de pedagogias pós-críticas ${ }^{12-14}$, são a expressão inequívoca dessa decadência ideológica do pensamento moderno burguês. Tais pedagogias, apesar de possíveis diferenças entre elas, fundamentam-se notadamente na valorização da prática imediata e espontânea como processo construtor de conhecimento, defendendo a centralidade das interações discursivas e concebendo a escola como um espaço de compartilhamento e troca de crenças culturais e de saberes locais, cotidianos e populares.

A negação da objetividade em si do real (afirmando que as coisas não existem independentemente do sujeito, tornando todo o real uma construção subjetiva) e o relativismo ontológico (transformando a teoria do ser em uma nova teoria do conhecer, na medida em que ontologicamente a realidade é, para tais teorias intituladas "pós", construída a partir da própria experiência sensível do ser) assumidos por tais ideários pedagógicos atestam suas vinculações ao denominado período decadente da sociedade tardo-burguesa.

$\mathrm{Na}$ esteira dos embates de Lukács ${ }^{15}$ contra o neopositivismo e com base nas análises de Lênin ${ }^{16}$ contra o empiriocriticismo, ambos refutando o ceticismo e o epistemologismo de suas épocas, acreditase que o trabalho educativo pautado na pedagogia histórico-crítica não pode negar a dimensão ontológica que é própria da atividade de ensino.

Considerando que a ontologia se debruça sobre o processo de constituição e produção da realidade e tendo-se em vista que a educação, para a pedagogia histórico-crítica, é uma mediação da prática social, esta que é ponto de partida e ponto de chegada do trabalho educativo, a atividade de ensino sempre se realiza concretamente por um horizonte ontológico de compreensão dessa prática social. Tal aspecto é válido para a relação entre ensino e aprendizagem, ou seja, tanto para professor quanto para alunos.

Nessa perspectiva, a atividade de aprendizagem possibilita aos alunos a apropriação dos conteúdos escolares necessários para o conhecimento da realidade (dimensão epistemológica) e, ao mesmo tempo, a apreensão dos nexos e relações que lhe permitem compreender e explicar o que essa realidade realmente é (dimensão ontológica).

Quanto ao professor, haja vista a realização da atividade de ensino, assumir a orientação teóricometodológica da pedagogia histórico-crítica no trabalho educativo implica não somente "conhecer" a aparência da prática social, mas, sobretudo, apreender o que essa prática social realmente é, considerando esse ser em sua processualidade histórica, ou seja, em seu surgimento, desenvolvimento, estrutura atual e tendências futuras de transformação (tal qual delineado por Marx ao longo de seu percurso teórico-metodológico, ao buscar apreender seu objeto de análise para além da aparência dos fenômenos que se manifestam empiricamente e são captáveis fenomenicamente pela nossa percepção). Implica não apenas deter informações caóticas e precárias dessa prática social, mas também compreendê-la como síntese de múltiplas relações e determinações numerosas.

Conforme Duarte ${ }^{17}$, há uma relação intrínseca entre a educação escolar e a formação da concepção de mundo dos indivíduos que está fundada em uma dada dimensão ontológica da realidade. Com efeito, a aquisição dos conhecimentos mais desenvolvidos no campo das ciências, das artes e da filosofia, tanto por parte dos professores quanto dos alunos, é fundamental para a formação de uma concepção de mundo que torne possível a compreensão de questões ontológicas fundamentais, tais 
como as reveladas nas perguntas: Que sociedade é esta? Como ela se formou? O que é a realidade? O que é o homem?

Quanto mais o trabalho educativo escolar disponibilizar aos alunos conhecimentos que possibilitem a eles responder tais questões de maneira não fantasiosa, não ilusória, não mistificada e não folclórica - ou seja, disponibilizar aos alunos instrumentos teóricos, por meio da mediação do conhecimento científico, artístico e filosófico, de forma tal que as respostas a essas perguntas cada vez mais tenham aproximação objetiva e concreta com o próprio real, o que exige um "método" adequado para tal -, mais nós estaremos contribuindo para a formação de uma concepção de mundo baseada não na aparência dos processos sociais e naturais da realidade, mas sim na sua essencialidade concreta.

A perspectiva materialista, histórica e dialética da atividade de ensino proposta pela pedagogia histórico-crítica não autoriza nenhum tipo de silenciamento sobre a realidade concreta ao não separar o conhecimento sobre o mundo (dimensão epistemológica) da existência efetiva deste próprio mundo (dimensão ontológica), vistas as relações entre os conteúdos escolares e a totalidade da atividade humana historicamente desenvolvida.

Sendo assim, a pedagogia histórico-crítica não segue o fluxo das correntes filosóficas e pedagógicas hegemônicas do período da decadência ideológica do pensamento moderno, tais como o positivismo, o neopositivismo, o pragmatismo, o conhecimento tácito, o construtivismo, o pós-modernismo, entre outras. O processo de transmissão-assimilação do saber por meio do trabalho educativo escolar não deve nem pode fragmentar a dimensão ontológica da dimensão epistemológica, separando ciência e visão de mundo ${ }^{17}$.

A cisão entre epistemologia e ontologia ou entre conhecimento e visão de mundo somente acentua a redução das atividades humanas, plasmadas fenomenicamente naquilo que se torna empiricamente sentido e observado, aos limites da imediaticidade da vida cotidiana. Com isso, a práxis humana torna-se restrita ao seu emprego utilitário e direto, carente de mediações, restringindo o conjunto das atividades dos indivíduos singulares e a totalidade da prática social humano-genérica à funcionalidade prática imediata, manipulatória e utilitária, minimizando as forças motrizes do desenvolvimento histórico da humanidade.

O trabalho educativo fundamentado em concepções pedagógicas que operam a cisão entre epistemologia e ontologia e que se silenciam acerca das questões relativas à visão de mundo também reduzem a atividade de ensino a um amontoado de técnicas e procedimentos de manipulação imediata e pragmática que, no máximo, podem contribuir para o processo de sociabilidade adaptativa dos indivíduos às condições que pautam suas vidas cotidianas. As pedagogias hegemônicas do "aprender a aprender", notadamente, acentuaram essa "práxis manipulatória" da atividade de ensino, trazendo consequências nefastas para o processo formativo dos indivíduos.

Com efeito, a práxis manipulatória está presente na história do desenvolvimento da humanidade, desde o surgimento da vida primitiva até a vida moderna e, como tal, não pode ser eliminada do conjunto da totalidade social que determina a vida humana. Por certo, a manipulação da natureza pelo homem primitivo caracterizou-se como um ato fundamental de apropriação da natureza e objetivação da cultura humana. Na vida moderna, ainda somos acometidos a realizar atividades em nossa vida cotidiana que atendem a função de manipulação direta e imediata, como utilizar objetos comuns, por exemplo.

Segundo Coutinho 7 , tais atividades imediatas, caracterizadas como manipulatórias, não exigem o conhecimento das determinações essenciais do objeto ou do fenômeno com o qual o ser humano se depara e se relaciona e, assim, não necessitam de uma representação mais rica da realidade. A atividade manipulatória acaba por se decompor em unidades simples imediatamente utilizáveis, cumprindo sua finalidade a partir da realização de ações de elementos isolados ou diretamente combináveis, sem a necessidade de mediações mais complexas.

Evidentemente, a manipulação não se constitui como um mal em si mesma. Não obstante, no processo histórico de desenvolvimento da humanidade, novas formas de atividade mais ricas e complexas se constituíram. Estas, caracterizadas como "práxis apropriadoras", exigem e permitem aos homens a captação das ricas determinações do objeto ou fenômeno, tornando lógica a correta consciência do significado humano e social da práxis. Atividades humanas como a ciência, a arte, a 
filosofia, a política, bem como o ensino sistematizado, necessitam levar em conta e explicitar a riqueza da objetividade da coisa em si.

Atividades ricas em determinações e mediações numerosas não podem ser produzidas e reproduzidas diretamente, no nível da manipulação imediata, sob o risco do empobrecimento simultâneo da própria essência de tais atividades. Conforme nos esclarece Coutinho:

A distinção entre práxis apropriadora e práxis manipulatória implica, por sua vez, a distinção entre diferentes níveis de racionalidade. A maior ou menor apreensão racional do objeto pelo pensamento relaciona-se com a amplitude dos objetivos propostos na práxis. Assim, quanto mais ampla for a práxis, quanto mais profunda e organicamente se vincula ao objeto, tanto mais rico deverá ser o sistema de categorias racionais que ela colocará em operação. (p. 94)

O empobrecimento da práxis humana apropriadora, por certo, corresponde à eliminação da configuração ontológica da objetividade. Ao fazer isso, o pensamento não apreende o objeto em sua riqueza categorial, em sua totalidade, como unidade da diversidade e como síntese entre conteúdo e forma, empobrecendo a atividade humana ao nível da manipulação, dividida, formalizada e reduzida à pura forma, carente de seus conteúdos concretos. No trabalho educativo escolar, a atividade de ensino deve ser um reflexo na consciência do sujeito (professor) das determinações ontológicas objetivas e universais dessa práxis humana configurada como mediação da totalidade do real, ou, nas palavras de Saviani ${ }^{1}$, como mediação da prática social global.

É nesse sentido que o método da pedagogia histórico-crítica não pode ser convertido em cinco passos realizados sequencialmente e de forma mecânica, em que primeiro 1) parte-se da prática social, depois 2) problematiza-se, logo após 3) instrumentaliza-se, depois 4) faz-se a catarse para, em sequência, 5) retornar à prática social. Tampouco é possível estabelecer uma norma de ensino dos conteúdos escolares fundamentando-se na pedagogia histórico-crítica, de modo a se preparar um plano de aula para cada um dos passos do método pedagógico.

Temos acompanhado, ao longo dos últimos anos em nossas atividades de pesquisa e ensino na formação inicial e continuada de professores, certa ansiedade por encontrar exemplos e modelos de aplicabilidade dessa teoria pedagógica na prática em sala de aula, por parte daqueles que desejam desenvolver seu trabalho pedagógico com base na pedagogia histórico-crítica. Nossa resposta a esse anseio costuma ser: há que se dominar a teoria para que se possa desenvolvê-la na prática.

O que queremos salientar é a impossibilidade de materialização de aulas embasadas na pedagogia histórico-crítica sem o fecundo domínio de seus fundamentos teóricos, que são exatamente os pilares constitutivos do método pedagógico em questão. O arsenal categorial teórico é que possibilita colocar em movimento o método na sua atividade de ensino, enriquecendo a prática pedagógica coerentemente à luz da teoria.

Questiona-se, portanto, a existência de uma formalização da didática da pedagogia históricocrítica, devido à impossibilidade de sua existência autônoma e isolada, sem referência, relação e mediação orgânica com seus fundamentos teóricos. Qualquer tentativa de aplicação do método pedagógico sem domínio dos fundamentos da teoria (da qual o próprio método é constitutivo) resulta, em nosso entendimento, tanto na sua didatização quanto na sua desmetodização. Tal fato pode ocorrer quando, por exemplo, seu método pedagógico acaba sendo "encaixado" em um estruturalismo esquemático que reduz a atividade pedagógica a uma simples técnica de manipulação. Trata-se, aqui, de uma operação lógico-formal do pensamento, quando este toma como objeto suas próprias regras imanentes, suspendendo o real como objeto da própria atividade e em nada afirmando nexos com a estrutura ontológica da realidade.

O resultado da formalização do método da pedagogia histórico-crítica se converte em um procedimento didatizado parcial, unilateral e imediato, em que a 'práxis' docente acaba se convertendo em uma atividade técnica empobrecida de manipulação de passos de ensino reduzidos às regras formais pseudo-objetivas, ou seja, regras com propenso caráter objetivo; mas que, no fundo, são estabelecidas ao gosto subjetivo do professor, que passa a delimitar por vontade própria o 
momento de reconhecer ou partir da prática social inicial dos alunos, problematizar, instrumentalizar, possibilitar a catarse e, por fim, permitir a eles a manifestação de uma nova prática social (final).

Assim, uma racionalidade técnica passa a substituir o método dialético, em que o imediato, o espontâneo e o linear acabam por fragmentar o que deveria ser um único e orgânico movimento, rico em mediações e contradições, tornado, agora, uma coleção de passos convertidos em procedimentos e técnicas de ensino.

Considerando a prática social - ponto de partida e ponto de chegada do trabalho educativo para a pedagogia histórico-crítica - um conjunto de complexos articulados que constituem uma totalidade social (um complexo de complexos), exige-se do professor a apreensão consciente dos dados constitutivos dessa realidade e de suas ricas mediações e relações entre os complexos que a formam em uma totalidade única e orgânica: a totalidade da vida social.

Dito isso, há de se reconhecer as diferentes posições e relações recíprocas entre professor e aluno que colocam em movimento o método pedagógico histórico-crítico, a partir da análise do duplo trânsito requerido pela atividade educativa referente ao caminho lógico do ensino, em contraposição dialética ao da aprendizagem, processo dinamicamente promotor de desenvolvimento humano, tal como é proposto por Martins ${ }^{18}$, com base no aporte metodológico materialista dialético que fundamenta a psicologia histórico-cultural, a teoria da atividade de Leontiev ${ }^{4-5}$ e os princípios da pedagogia históricocrítica. Sobre tais questões discorreremos na sequência.

\section{O método pedagógico histórico-crítico: contribuições da psicologia histórico-cultural e da teoria da atividade}

Ao debater a natureza e a especificidade da educação, Saviani² evidencia a relação histórica e ontológica entre a natureza da educação e a natureza dos próprios homens. Estes necessitam produzir continuamente sua própria existência por meio das atividades de trabalho e precisam também aprender a produzir essa existência, o que nos permite concluir que tal processo é educativo. Partindo dessa relação, podemos afirmar que a natureza do trabalho educativo corresponde ao " [...] ato de produzir, direta e intencionalmente, em cada indivíduo singular, a humanidade que é produzida histórica e coletivamente pelo conjunto dos homens." (p. 13).

A especificidade da educação, por seu turno, tem correspondência com a questão do saber (o conhecimento), cuja compreensão deve estar relacionada ao próprio desenvolvimento histórico objetivo da humanidade. Essa análise histórica nos permite reconhecer, no âmbito da especificidade da educação, que o papel da educação escolar, como a forma mais desenvolvida historicamente de educação, é para a pedagogia histórico-crítica a socialização do saber sistematizado.

Com efeito, o saber sistematizado se diferencia de outros tipos de saberes (como o saber espontâneo ou religioso) por ser produzido por um conjunto de atividades específicas dos homens, quais sejam, a ciência, as artes e a filosofia, resultantes de um longo processo de complexificação da prática humana que se acumula historicamente na prática social.

Na sociedade moderna, não sem contradições, a escola assumiu a função - que lhe é específica de socialização desse saber sistematizado. Para tanto, Saviani já alertara que o objeto específico da educação, por um lado, tem a ver com a identificação dos elementos culturais - os conhecimentos - que necessitam ser apropriados pelos indivíduos das novas gerações e, por outro, com a descoberta das formas mais adequadas para promover o processo de apropriação desses elementos.

Por certo, o trabalho educativo exige uma atividade especificamente humana que possa articular dialeticamente a relação conteúdo e forma na socialização do saber sistematizado, atividade norteada por finalidades (objetivos a atingir) e que esteja organizada de modo a articular e colocar em movimento os processos de ensino (transmissão) e aprendizagem (apropriação) desse saber, agora convertido em saber escolar.

Entendemos que as intermediações da pedagogia histórico-crítica com a psicologia históricocultural e, no âmbito dessa última, as contribuições da teoria da atividade de Leontiev ${ }^{4-5}$ apresentam-se $^{2}$ como um riquíssimo estofo teórico para se pensar a organização da atividade pedagógica de ensino 
e aprendizagem, colocando em movimento o método pedagógico necessário para a apreensão dos fenômenos em sua essencialidade concreta.

Defende-se aqui que a teoria da atividade ${ }^{4,5}$ é um grande contributo para a organização da prática pedagógica que se pretende fundamentada pela pedagogia histórico-crítica, pois esta nos possibilita pensar o trabalho educativo como uma atividade especificamente humana e, ao mesmo tempo, permite-nos reconhecer a especificidade dessa atividade que se materializa no ensino (atividade do professor) e na aprendizagem (atividade do aluno).

Para Leontiev ${ }^{4}$, todo o desenvolvimento humano ocorre por meio de uma atividade. Em determinados períodos de nossas vidas, algumas atividades ocupam lugar de atividades-guia, consideradas aquelas que, em um momento específico, requerem e determinam as principais mudanças promotoras de desenvolvimento de nosso psiquismo e personalidade.

Leontiev ${ }^{5}$ afirma que toda atividade humana possui uma estrutura geral carregada de traços essenciais constitutivos de sua especificidade e que, em unidade e em sua totalidade, caracterizamse como uma atividade. Esses traços essenciais da atividade humana são: o "objeto" da atividade, a "finalidade", seus "motivos", suas "ações" e suas "operações".

Compreender o trabalho educativo como atividade humana exige que pensemos a sua organização a partir da delimitação do objeto do ensino e da aprendizagem - correspondentes aos conhecimentos sistematizados dos fenômenos da realidade objetiva e convertidos em conteúdos escolares -; qual a sua finalidade definidora dos objetivos do ato educativo que, ao coincidirem com o objeto da atividade (os conteúdos escolares), promovem os motivos do ensino e da aprendizagem; e as formas pelas quais o ensino e a aprendizagem se realizam, visando explicitar quais ações e operações (procedimentos de ensino) devem ser realizadas por professores e alunos diante das tarefas escolares que pretendem concretizar o processo de transmissão e apropriação do conhecimento.

Compreendida dessa maneira, a estrutura da atividade pedagógica conquista a qualidade de mediação como interposição que gera transformação, na medida em que ensino e aprendizagem configuram-se como ato intencional mediado por signos (conteúdos escolares tomados como objeto da atividade), vinculado a uma finalidade (objetivos do ensino) e uma necessidade (motivos da aprendizagem) e organizado para realizar determinadas ações e operações (tarefas e procedimentos de ensino e aprendizagem).

Nessa condição de mediação, o trabalho educativo cumpre a tarefa de possibilitar a apropriação, por parte dos indivíduos singulares, da experiência humana genérica que é produzida pelo conjunto dos homens, por intermédio da particularidade do ensino e da aprendizagem, materializando o conceito de educação como mediação da prática social global, delimitado por Saviani'.

Considerando que o método em Marx ${ }^{3}$ fundamenta a pedagogia histórico-crítica, para essa teoria pedagógica, a construção do conhecimento pressupõe três momentos intimamente articulados: o ponto de partida que se dá no âmbito do conhecimento acerca do real sensível em sua aparência e manifestação fenomênica, imediata e aparente, a ser superado pela mediação de abstrações do pensamento (ideias, teorias), intentando alçar o conhecimento do real em sua essencialidade concreta, isto é, como síntese de múltiplas relações e determinações diversas. Em um percurso que contempla o movimento indutivo (do particular para o geral) e dedutivo (do geral para o particular), o critério de validação do conhecimento assim construído ocorre no âmbito do real, apreendido agora não mais de forma sensível e aparente.

Transposto esse percurso metodológico para a esfera pedagógica, depreende-se os três momentos que Saviani² denomina como síncrese, análise e síntese. Essa proposição, por sua vez, encontra amparo também na psicologia histórico-cultural ${ }^{18}$, que, ao tratar do desenvolvimento do pensamento, aponta a síncrese como forma inicial e primeva de pensamento, a ser superada por novas estruturas de generalização, tendo em vista atingir sua forma mais completa e complexa representada pelo pensamento abstrato, apto à captação dos fenômenos por meio de um sistema de conceitos.

Ainda com base em Martins ${ }^{18}$, depreendemos que ensino e aprendizagem são processos opostos interiores um ao outro e, operando por contradição, caracterizam-se por percursos lógicometodológicos inversos. A saber: a aprendizagem ocorre da síncrese para a síntese pela mediação da análise oportunizada pelas apropriações dos conhecimentos historicamente sistematizados, enquanto 
o ensino deve ocorrer a partir da síntese formulada por quem ensina, visando a superação da síncrese, própria ao momento inicial de construção do conhecimento de quem aprende. A síntese como ponto de partida do ensino resulta, por sua vez, da objetivação das apropriações já realizadas pelo professor, apto a promover o desenvolvimento do pensamento pela mediação do ensino escolar.

Assim, a dinâmica interna da atividade pedagógica vai se concretizando ao longo do percurso de escolarização (cujo início se dá na Educação Infantil), considerando que na base desse processo residem os conteúdos disponibilizados pelo ensino, que se voltam à formação de domínios e habilidades psicofísicas operacionais, mas que, à medida do desenvolvimento da criança, devem ser gradualmente superados pelos conteúdos conceituais, para que haja a formulação do conhecimento teórico-conceitual pela via das abstrações.

Esse percurso demanda, por conseguinte, que a atenção ao destinatário (aquele que aprende) leve em conta as atividades-guia que pautam a periodização histórico-cultural do desenvolvimento, bem como se tenha clareza de que os modos de pensar mudam ao longo da vida. Vygotski ${ }^{19}$, referindose a tais mudanças, formulou a periodização do desenvolvimento do pensamento, a pressupor: pensamento sincrético, pensamento por complexos e pensamento abstrato.

Esse avanço nos alcances do pensamento demanda um longo processo formativo que se estende, segundo Vygotski ${ }^{19}$, até a adolescência, quando o pensamento alcança as possibilidades para operar por meio dos conceitos propriamente ditos, isto é, caminha para alçar o mais alto grau de abstração do pensamento. Para Vygotski e demais estudiosos da psicologia histórico-cultural, o pensamento abstrato ou lógico-discursivo representa o pensamento na exata acepção do termo, uma vez que, ao ultrapassar a esfera das ações práticas e das imagens sensoriais, torna possível a apreensão dos fenômenos para além das aparências, ou seja, em sua essencialidade concreta como síntese de múltiplas relações.

\section{Considerações finais}

O percurso que avança do pensamento sincrético ao pensamento abstrato não resulta de determinantes naturalmente disponibilizados pela herança biológica ou por critérios cronológicos, mas da qualidade das mediações que ancoram a relação sujeito-objeto, da natureza dos vínculos entre o indivíduo e suas condições de vida e de educação. Destaca-se, pois, que o pensamento abstrato é uma conquista resultante das apropriações das objetivações simbólicas, que carecem de transmissão por outrem, que demandam ensino.

Não por acaso, Vygotski ${ }^{19}$ enfatizou uma diferença radical entre o ensino que se volta para os conceitos espontâneos e de senso comum e o ensino dos conceitos científicos, denominados por ele de "verdadeiros conceitos". Em seus estudos sobre o desenvolvimento do pensamento, o autor evidenciou a natureza dos conteúdos que devem ser priorizados por uma educação desenvolvente, que são os conceitos científicos. A formação de tais conceitos exige e articula-se a uma série de funções psíquicas como, por exemplo a da percepção complexa, da atenção voluntária, da memória lógica e, sobretudo, das operações lógicas do raciocínio, isto é, da análise, síntese, comparação, generalização e abstração. Por isso, Vygotsky destacou que, diante de processos tão complexos, o processo de instrução escolar que de fato vise a esse desenvolvimento não pode ser simples.

Diferentemente dos conceitos espontâneos, que se formam de modo assistemático pela simples inserção do sujeito na comunidade cultural, orientando-se por sua aplicação prática e pragmática, a formação dos conceitos científicos subjuga-se à orientação conscientemente dirigida, à voluntariedade e ao autodomínio da conduta - esferas que se revelam extremamente frágeis na adoção dos primeiros.

Tal qual para Marx ${ }^{3}$, o processo do conhecimento ocorre por meio de sucessivas aproximações, orientado a ascender do imediato ao mediato por meio da elevação do abstrato ao concreto. $O$ trabalho pedagógico desenvolvido e sustentado pelo método da pedagogia histórico-crítica requer a mediação da teoria para a superação da empiria fenomênica da ação humana.

Ademais, salienta-se que o método assim concebido encerra articulações internas entre teoria do conhecimento e ações práticas orientadas por ela, realizando-se mediatamente por ações sistematizadas em conformidade com o planificado. É no âmbito dessa sistematização que a didática 
desponta como instituinte e constitutiva do método e, portanto, a ele subordinada. Por isso, sua implementação como esteira do ensino requer professores saturados de determinações e mediações que explicitem o dinamismo e o movimento dos objetos e fenômenos do real concreto na prática pedagógica, revelando a processualidade mediadora da natureza ontológica do trabalho educativo.

\section{Colaboradores}

Ambos os autores participaram integral e conjuntamente da construção e preparação do artigo para sua publicação.

\section{Referências}

1. Saviani D. Escola e democracia. 41a ed. Campinas: Autores Associados; 2009.

2. Saviani D. Pedagogia histórico-crítica: primeiras aproximações. 11a ed. Campinas: Autores Associados; 2013.

3. Marx K. Grundrisse: manuscritos econômicos de 1857-1858: esboço da crítica da economia política. São Paulo: Boitempo; 2011.

4. Leontiev AN. O desenvolvimento do psiquismo. Lisboa: Livros Horizonte; 1978.

5. Leontiev AN. Actividad, consciência y personalidad. Ciudad de México: Editorial Cartago; 1984.

6. Lukács G. Existencialismo ou marxismo. São Paulo: Senzala LTDA; 1967.

7. Coutinho CN. O estruturalismo e a miséria da razão. 2a ed. São Paulo: Expressão popular; 2010.

8. Hungaro EM. A questão do método na constituição da teoria social de Marx. In: Cunha C, Sousa JV, Silva MA, organizadores. O método dialético na pesquisa em educação. Campinas: Autores Associados; 2014. p. 15-78.

9. Netto JP. Introdução ao estudo do método de Marx. São Paulo: Expressão Popular; 2011.

10. Lukács G. Marxismo e teoria da literatura. Rio de Janeiro: Civilização Brasileira; 1968. 
11. Duarte N. Vigotski e o "aprender a aprender": crítica às apropriações neoliberais e pós-modernas da teoria vigotskiana. 5a ed. Campinas: Autores Associados; 2011.

12. Corazza SM. Currículo como modo de subjetivação do infantil. In: Anais da 22a Reunião anual da associação nacional de pós-graduação e pesquisa em educação; 1999; Caxambu, Brasil. Caxambu: ANPEd; 1999

13. Silva TT. Documentos de identidade: uma introdução às teorias do currículo. 2a ed. Belo Horizonte: Autêntica; 2002.

14. Paraíso MA. Pesquisas pós-críticas em educação no Brasil: esboço de um mapa. Cad Pesqui. 2004; 34(122):238-303.

15. Lukács G. Para uma ontologia do ser social I. São Paulo: Boitempo; 2012.

16. Lênin VI. Materialismo e empiriocriticismo: notas críticas sobre uma filosofia reaccionária. Lisboa: Edições Avante; 1982.

17. Duarte N. A importância da concepção de mundo para a educação escolar: porque a pedagogia histórico-crítica não endossa o silêncio de Wittgenstein. Germinal (Salvador). 2015; 7(1):8-25.

18. Martins LM. O desenvolvimento do psiquismo e a educação escolar: contribuições à luz da psicologia histórico-cultural e da pedagogia histórico-crítica. Campinas: Autores Associados; 2013.

19. Vygotski LS. Obras escogidas. Tomo II. Madrid: Visor; 2001.

Lavoura TN, Martins LM. La dialéctica de la enseñanza y del aprendizaje en la actividad pedagógica histórico-crítica. Interface (Botucatu). 2017; 21(62):531-41.

Explicitando las intermediaciones entre la pedagogía histórico-crítica y la psicología histórico-cultural a partir de los fundamentos del materialismo histórico-dialéctico, el artículo pretende problematizar la dialéctica de la enseñanza y del aprendizaje en la actividad pedagógica. Se busca contribuir a la superación del problema de la escisión entre ontología y epistemología al señalar la necesidad de la sólida comprensión de los fundamentos del método de ascensión de lo abstracto a lo concreto, al paso que se afirma la teoría de la actividad como base teórica imprescindible para pensar la organización de la actividad pedagógica de la enseñanza y del aprendizaje en el ámbito de la educación, poniendo en movimiento el método pedagógico necesario para la aprehensión de los fenómenos como síntesis de múltiples determinaciones y relaciones numerosas.

Palabras clave: Método. Actividad pedagógica. Enseñanza. Aprendizaje. 
